\title{
Experimental evaluation of the buckling phenomena in the new joint design for upper deck structure of a bridge
}

\author{
L. Solazzi
}

Università degli Studi di Brescia, Facoltà di Ingegneria, dipartimento di Ingegneria Meccanica $\mathrm{e}$ Industriale, Via Branze 38, 25123 Brescia, Italy

\begin{abstract}
This paper is concerned with the experimental mechanical analysis of a new design of a joint for a main components of a upper deck of a road bridge. These components are subject to the compression state stress induced by the weight and the load acting on the road. Each upper deck of a bridge (positioned on each side of the bridge) is composed by four tubular structures that must be joint each together. The joint must to take in to account many aspects, for example that the length of each component is not the same (because, obviously, there is a mechanical tolerance). This phenomena induce different compression stress on each component and so is very important non only the critical buckling load but also the post buckling behaviour of the structure. It is very important that if a single tubular structure reaches the critical load of instability, it still has load capacity. This is to avoid that, in the case where a column reaches the instability, the entire load acting on a column increase the load on the remaining three. For this purpose many different geometrical solutions have been designed (elaborated by fem analyses and successively tested experimentally). This work reports the main experimental results on the best joint solution and how this increase the load capacity and the displacement respect to the solution without this flange.
\end{abstract}

\section{Introduction}

The Figure $\mathrm{n}^{\circ} 1$ reports the design of the bridge. The width is $120 \mathrm{~m}$ and the upper deck (positioned on each side of the bridge) is composed by four tubular structure. The size of circular tubular structure are : external diameters $500 \mathrm{~mm}$, thickness $12.5 \mathrm{~mm}$, length $12 \mathrm{~m}$, maximum load applied $3080 \mathrm{kN}$ (including both the dead load and the external load).

In general, the buckling phenomena and in particular the behavior of buckling and post buckling phenomena is a very difficult problem. There are many different theories that explain this phenomena such of these are in $[1,2,3,4,5]$. To understand the buckling phenomena is possible to use a very sophisticated software like Abaqus which is specific for non linear analysis [6,7]. Nevertheless there are many different aspects that influence the results and do not permitted the "exact" correlation between the predicted value (by theories or fem analyses) with the experimental results.

The main factor is the initial imperfection, always present in the real structures, whose size or intensity change both the critical buckling load and both the post buckling behaviour [8,9,10]. For this reason the experimental tests are very important and indispensable for the most important works.

This is an Open Access article distributed under the terms of the Creative Commons Attribution-Noncommercial License 3.0, which permits unrestricted use, distribution, and reproduction in any noncommercial medium, provided the original work is properly cited. 
The goal of this work is to verify a special flange of interface between the tubular structures, and in particular how this geometrical solution increase the load capacity in the post buckling area in the force/displacement diagram. The main steps of this experimental work are: design a specific bench tests; evaluation the mechanical behaviour for the flange and the tubular structure individually, and finally study the performance for tube joint with the flange.

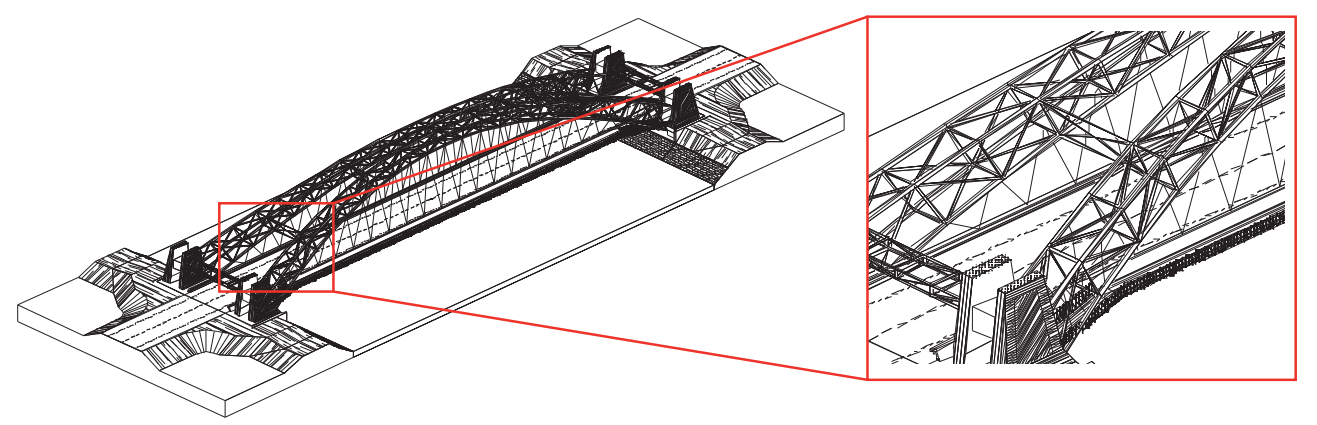

Fig. 1. Overview of the design of a new bridge.
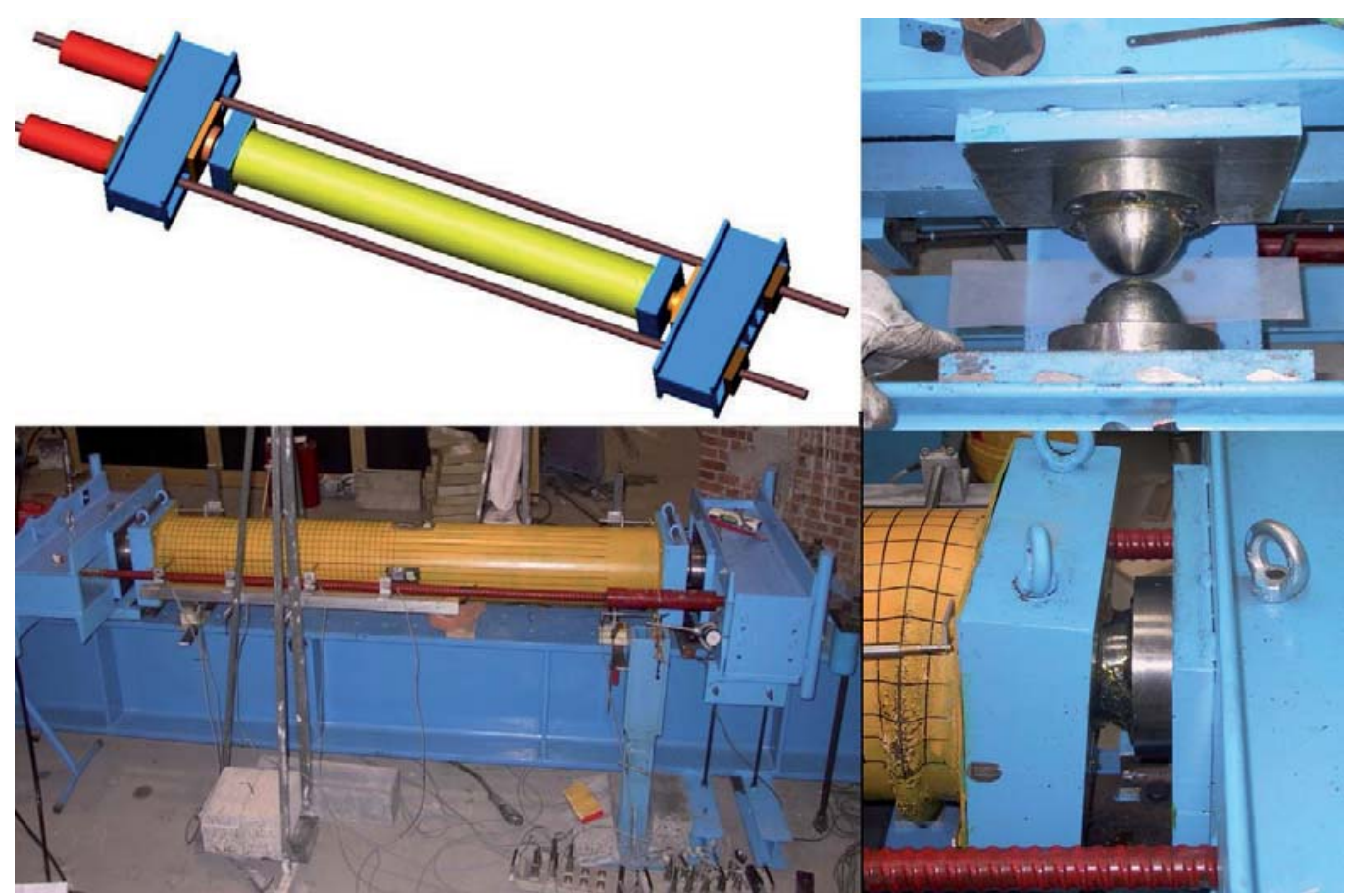

Fig. 2. Test bench and specimen.

\section{Experimental set up}

It is obviously that is impossible to test the real structure both the size and both the real load that is necessary apply to the tubular structure for induce the buckling phenomena. For this, a precise bench test was designed in order to made a specific experimental test. First of all is important to define how 
the buckling phenomena we want to study by the bench test. The ratio between the real geometry of structure and the geometry of the specimen vary, for example, in function if we want to study the local or global buckling. Because the main object of this study is the local joint between the tubular structures, we must maintain the same parameters of similarity that permitted the study of local buckling. The main parameters that govern the local buckling are: radius, thickness, length of the tube and yield strength of the material $[1,2,5,11,12]$. The ratio between the radius and the thickness of tube is about 29.8. The reason because this ratio is not the same value respect that is in the real geometry is that the component is commercial tube and so the dimensions are just fixed. The dimensions of the specimen are: length $=2000 \mathrm{~mm}$; external diameter $\approx 273 \mathrm{~mm}$ and the thickness $\approx 4.2 \mathrm{~mm}$; the material is a classical structural steel S275 JR EN 10027-1. The load applied to the specimen is generated by two hydraulic cylinders each of them with capacity of $600 \mathrm{kN}$. The constrains applied to the specimen are two hinges made by two special balls. The axial and bending stress on the tube, was acquired by several strain gauges positioning on it, while the displacement and rotate both the flange and both the tube was acquired by 14 LVDT.

\section{Tests on the flange junction}

The figure $\mathrm{n}^{\circ} 3$ shows the final geometry of the joint. The idea of this solution is to insert an element in the joint for increase the compliance; for compensate, for example, the different length of tubular elements. This element is implemented through a circular plate. It is supported by an appropriate blocks, which are fixed with screws to connect to the other end of the element, and the other side by a series of a triangular plate which are rigidity fixed to the element tube by welding. Many different numerical analyses were elaborate in order to define the geometry of each element that compose the joint. There are different problems to resolve, for example the geometry of the circular plate, number and size of the blocks, number and size of the triangular plate and so on. The object was to introduce a new "soft" element without introduce a critical point. For example if the length of the triangular plate ( welded in the inner tube) is small, instead of deforming the circular plate forming the plastic hinges, the square plate rotate outward and increasing the diameter of the tube; this solution in not acceptable ( Figure $n^{\circ} 4$ ).
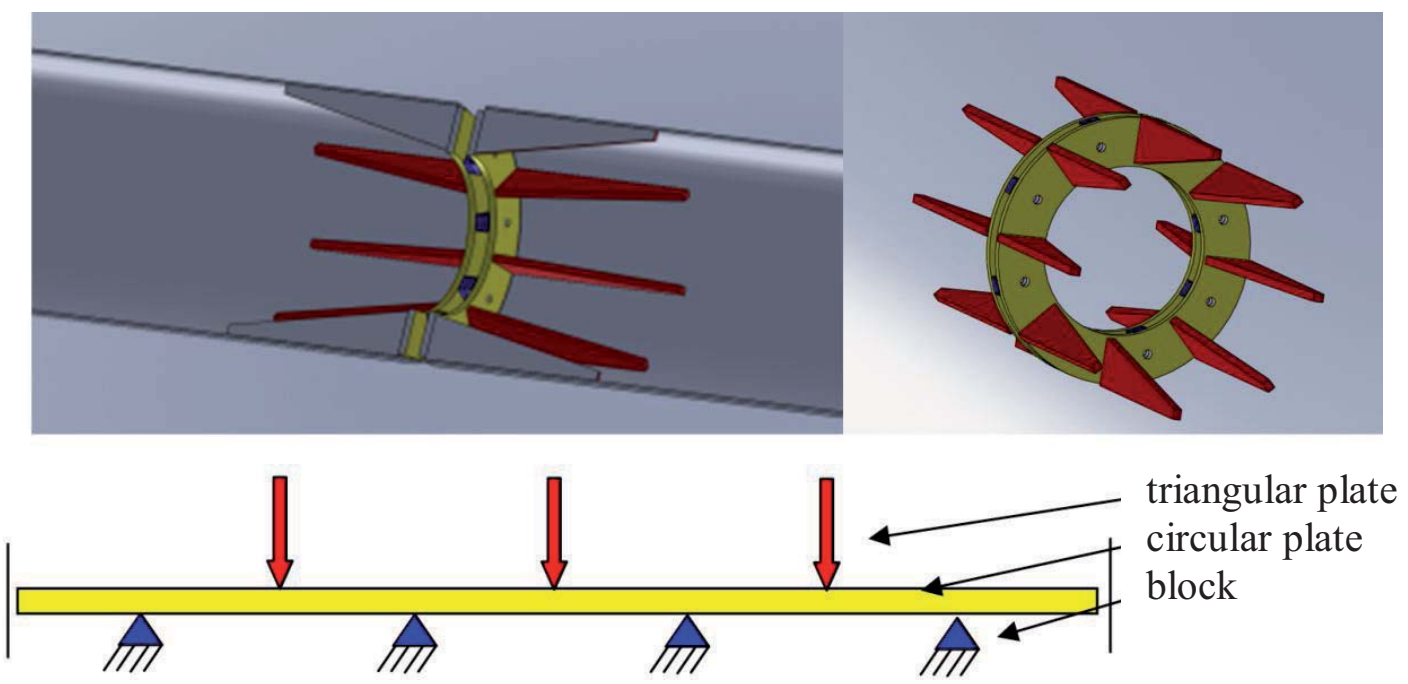

Fig. 3. Flange and relative schematization. 


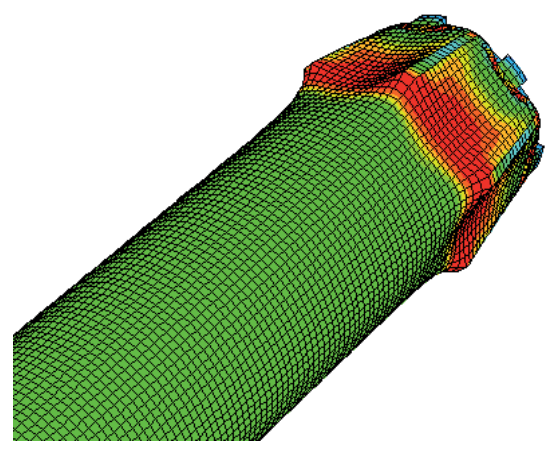

Fig. 4.Incorrect displacement of the joint.

\subsection{Experimental tests on the flange}

The figure $\mathrm{n}^{\circ} 5$ shows the experimental tests on limited portion of the pipe (total length $=350 \mathrm{~mm}$ ) in order to verify the mechanical behaviour of the flange. The figure shows the deformation at different load level, and in particular is important to observe that the deformation is concentrated in the area where there are no internal brackets for fixing the circular plate. In this case the mechanical behaviour of the joint is correct and the deformation, like figure $\mathrm{n}^{\circ} 4$ (that is incorrect), is avoid.

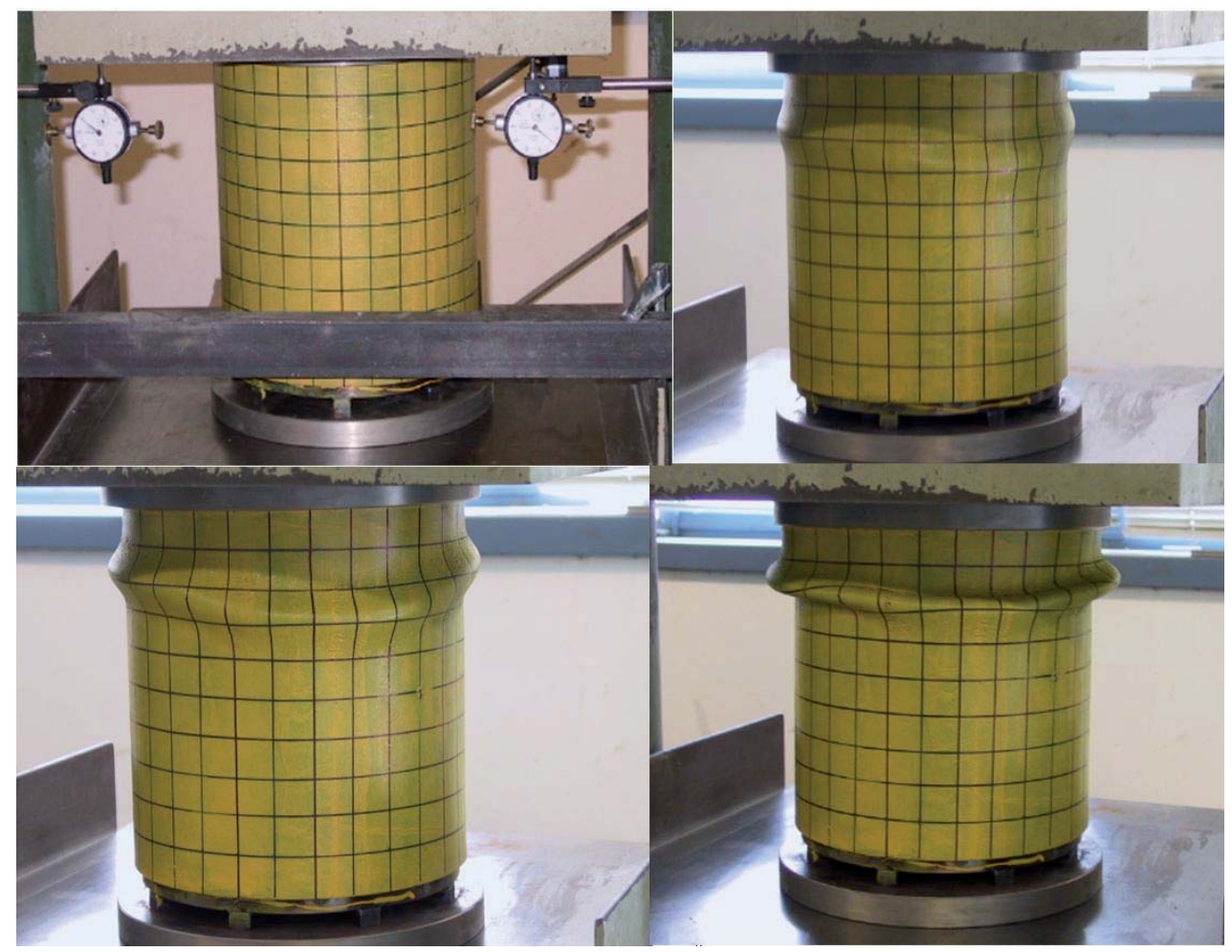

Fig. 5. Different displacement with different load level. 


\section{Tests on the tube without flange junction}

In order to analyse the whole behaviour (force vs. displacement) for the tube and the joint, the first analyses regards the tube, without the flange. For this purpose, two different pipe was analysed. The results, like pictures, are reported in figure $n^{\circ} 6$. The figure shows the deformation of the of the tube which is close at the end by a simple plate with the thickness is $4 \mathrm{~mm}$.

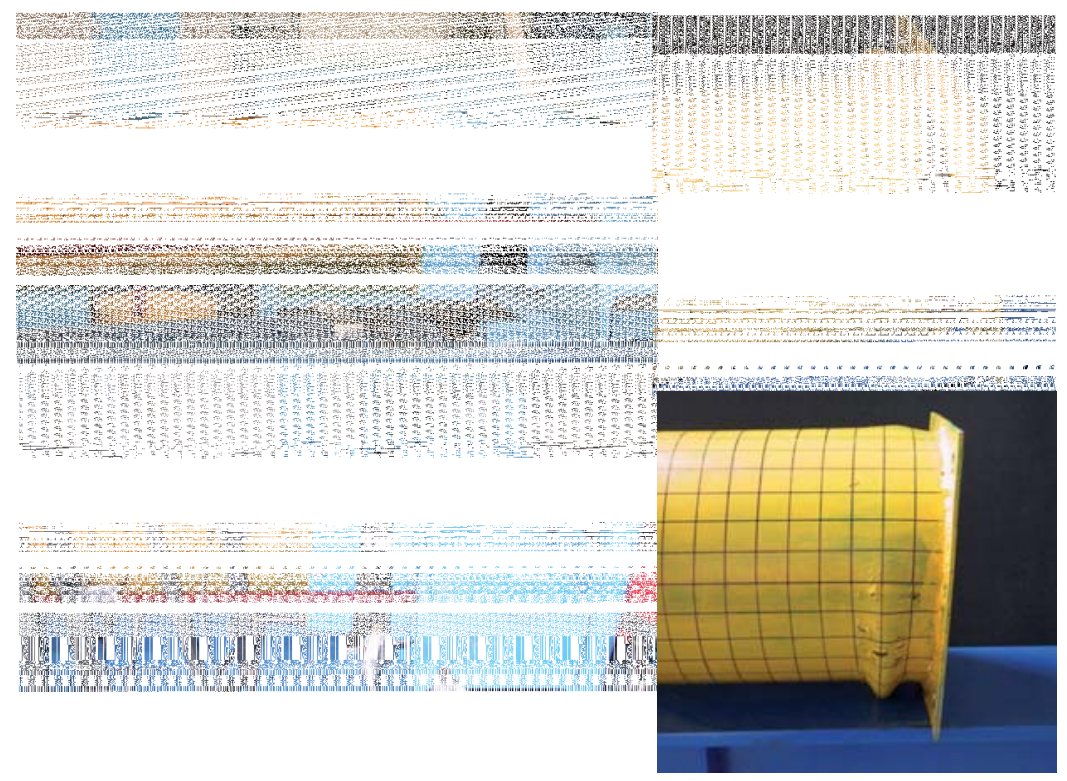

Fig. 6. Deformation of the tube without the flange.

\section{Tests on the tube with flange junction}

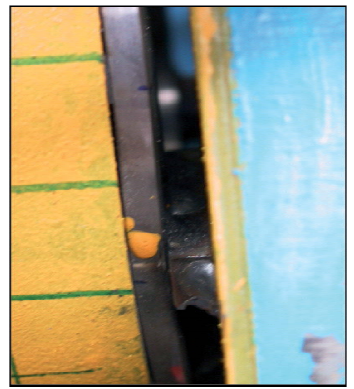

$600 \mathrm{kN}$

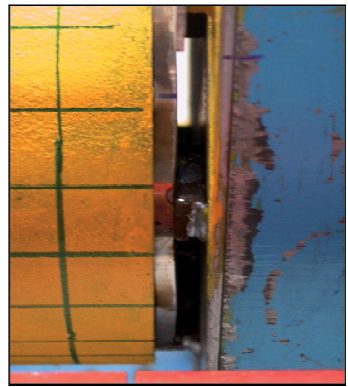

800 kN

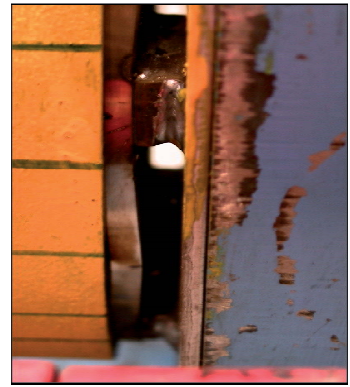

$920 \mathrm{kN}$

Fig. 7. Deformation of the flange at different load level.

The figure $n^{\circ} 7$ shows the deformation of the flange at different load level and in particular is possible to observe the formation of the plastic hinges in the circular plate and more specifically in the area supported by blocks. This aspect leads to a significant increase in the deformability of the structure without additional a critical point, like instability, in the whole joint. The figure $\mathrm{n}^{\circ} 8$ shows 
the displacement acquired in the external diameter along the axis of the tube. It is possible to observe that the displacement increase with the load and that the maximum value is positioned at about 50 $\mathrm{mm}$ from the circular plate, while the minimum is positioned at about $150 \mathrm{~mm}$.

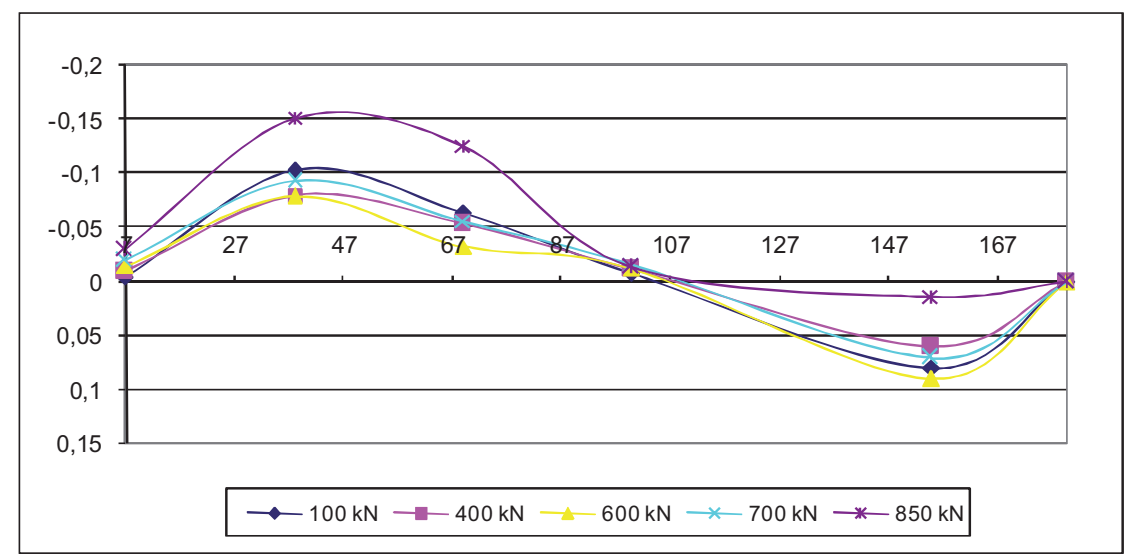

Fig. 8. Deformation along the tube in function of the load applied.

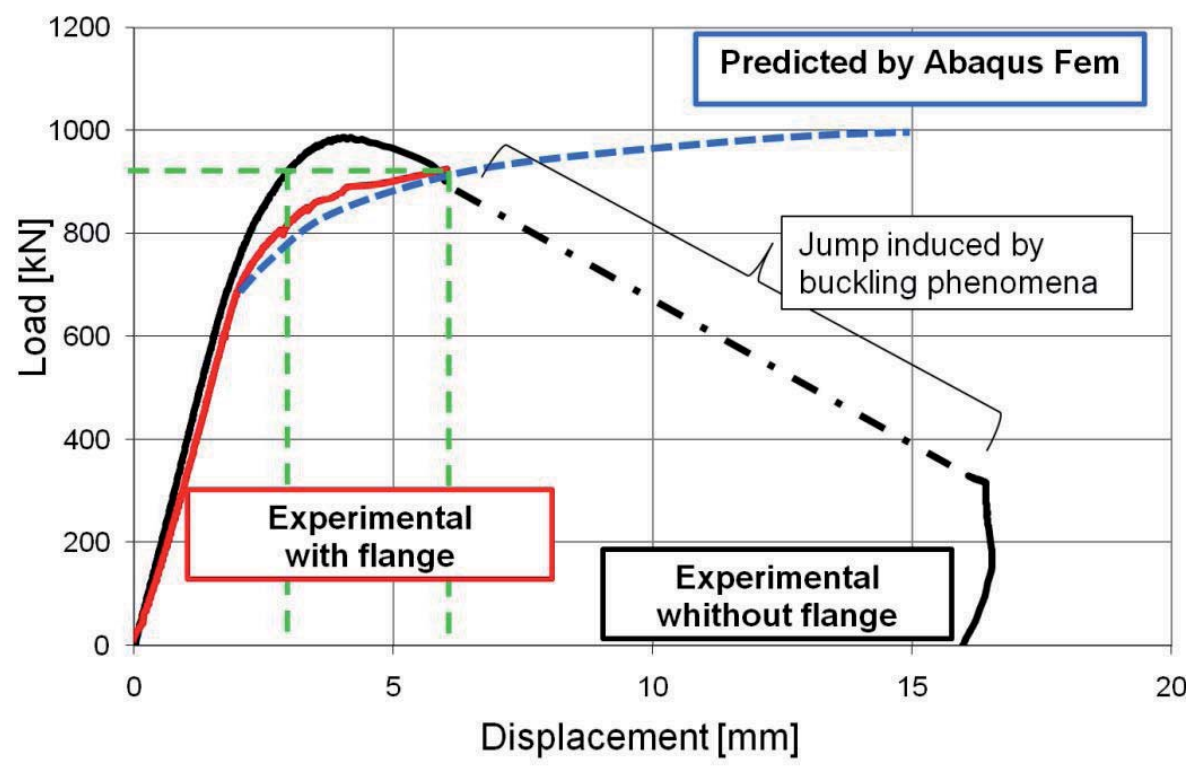

Fig. 9. Diagram force Vs displacement for different geometrical solution.

The figure $n^{\circ} 9$ shows the comparison between the numerical and experimental results.

The black line reports the experimental results for a joint without the flange (described in the p.to 4). The maximum load achieved is about $1000 \mathrm{kN}$, after that value, the load decrease. The line shows a jump induced by buckling phenomena which is very quick, and so the LVDT is not able to detect it. The residual displacement is about $15 \mathrm{~mm}$.

The red line shows the experimental results for the joint with the flange. In the linear elastic zone, the displacement is slightly higher than the solution without the flange, this indicate the compliance of the junction. The trend is growing without reaching a maximum absolute value. The maximum load applied is $920 \mathrm{kN}$ for technical problems. The value, or better, the trend predicted by fem 
analyses, by introducing the geometrical imperfections as a displacement with sinusoidal development along the axis of the tube, shows a good correlation with experimental data. The comparison shows that the proposed solution presents undoubted positive aspects, primarily related to compliance. At the maximum load (about $1000 \mathrm{kN}$ ) without the flange the displacement is about 4 $\mathrm{mm}$, while with the flange the displacement is about $15 \mathrm{~mm}$ without the danger of occurrence of the buckling phenomena. At $920 \mathrm{kN}$ (the maximum load at the test with the flange) the displacement changed from $3 \mathrm{~mm}$ to $6.1 \mathrm{~mm}$ with an increase about $100 \%$.

\section{Conclusions}

This paper reports a series of experimental results concerning a new type of connection between tubular element. The specifics requests in this connection are primarily related to the fact that is must be an "soft" element within the entire structure in order to compensate the different expansion between element that constitute the upper deck of a bridge. The results support the assertion that the new type of joint shows a significant increase both in performance and both to avoid the local buckling. Given the excellent results, the future developments concerning the study of experimental tests on as portion of junction of real geometry.

\section{References}

1. S. Timoshenko, J.M. Gere, Theory of elastic stability (Mc Graw Hill, New York, 1961)

2. G. Ballio, F.Mazzolani, Strutture in acciaio (Arnoldo Mondadori Editore, 1977)

3. J. C. McCormac Structural Steel design : LRFD Method (Harper Collins Publishers Inc., 1989)

4. O. Belluzzi, Scenza delle costruzioni (Zanichelli Editore, 1982)

5. ECCS (1981) European Recommendation for Steel construction, Buckling of Shells, Section 4.6 European convention for Constructional SteelWork

6. C. Massonet, M. Save, Calcolo plastico e a rottura delle costruzioni (Clup Editore 1980)

7. C.T.F. Ross, Finite element methods in structural mechanics (John Wiley sons Limited, England 1985)

8. P. Mandal, C.R. Calladine, Buckling of thin cylindrical shells under axial compression (International Journal of Solids and Structures 37 (2000) 4509-4525)

9. V. Tvergaard, A. Needleman, Buckling localization in a cylindrical panel under axial compression (International Journal of Solids and Structures 37 (2000) 6825-6842)

10. K. Seung-Eock, K. Chang-Sung, Buckling strength of the cylindrical shell and tank subject to axially compressive loads, (Thin Walled Structures 40 (2002) 329-353)

11. G.Lu, R. Mao, A study of the plastic buckling of axially compressed cylindrical shells with a thick -shell theory (International Journal of mechanical Sciences 43 (2001) 2319-2330)

12. Y. Xiang, C.M. Wang, C. W. Lim, S. kitipornchai, Buckling of intermediate ring supported cylindrical shells under axial compression (Thin Wall e Structures 43 (2005) 427-443) 